\title{
Pragmatismo jurídico aproximando thêMis e eros: O SENTIMENTO DO SUPREMO TRIBUNAL FEDERAL NA ADPF 54/DF
}

Juridical pragmatism bringing themis and eros closer:

The sentiment of the supreme federal court in ADFP 54/df

Nevita Maria Pessoa de Aquino Franca luna Mestre em Filosofia pela Universidade Federal da Paraíba e Doutoranda do Programa de Pós-Graduação em Direito da Universidade Federal de Pernambuco (UFPE).E-mail: nevitafranca@gmail.com

RECEBIDO EM:29/03/2014

APROVADO EM:17/02/2016

DOI: $10.5585 /$ RDB.V11 15.254

\section{RESUMO}

Ao longo de sua história, o pensamento ocidental e, especialmente, o pensamento jurídico privilegiou a razão sobre os sentimentos. E isso pode ser explicado pelo fato de que a razão sempre esteve calcada na invariabilidade e eternidade, enquanto que os sentimentos têm sido retratados como manifestações inconstantes e enganosas da natureza. Portanto, a maioria das visões jurídicas contemporâneas não dão a devida atenção a influência dos sentimentos na constituição de prescrições normativas, nem sequer levam em consideração a influência de experiências sensoriais no processo de tomada de uma decisão jurídica. No entanto, o presente artigo analisou em detalhe os argumentos utilizados nos votos dos dez ministros do Supremo Tribunal Federal (STF), durante o julgamento da Arguição de Descumprimento de Preceito Fundamental (ADPF) 54/DF, processo que reconheceu a inconstitucionalidade na interpretação segundo a qual a interrupção da gravidez de feto anencéfalo seria hipótese de aborto, conduta tipificada nos artigos 124, 126 e 128, incisos I e II, do Código Penal. O objetivo do trabalho foi analisar, sob uma perspectiva pragmática e contextualista, o acórdão deste caso emblemático, na tentativa de identificar o relevante papel dos sentimentos como fundamento utilizado pelos ministros do STF ao decidir hard cases. Quanto à metodologia utilizada, a ADPF 54/DF foi escolhida porque apresenta três características interessantes: (1) abordou questão polêmica, havendo fortes controvérsias sociais e políticas sobre o aborto e tendo a decisão motivado uma grande produção literária; (2) o STF, máxima instância recursal no Brasil e a quem cabe a interpretação da Constituição, julgou de maneira 
contrária à transcrição literal do Código Penal, (3) tratou de decisão não-unânime, com significativas divergências na argumentação, fundamentos contrastantes, expressiva carga emocional, dubiedade e confusão ao considerar os termos técnicocientíficos, ético-morais, filosóficos, religiosos e legais, o que levou a Corte a ouvir especialistas em diversas áreas. Assim, constatou-se que o Supremo Tribunal Federal harmonizou a esfera dos sentimentos com àquela da dogmática jurídica, através da aplicação do método pragmático, utilizando como base argumentativa a experiência das gestantes de fetos anencéfalos, as polêmicas provenientes da Ação Direta de Inconstitucionalidade (ADI) 3510/DF, a interdisciplinaridade com outros saberes (a medicina, a psicologia, a religião), a prudência e a equidade, desvinculando-se, por outro lado, da aplicação literal da lei.

Palavras-chaves: Sentimento, Direito, Suprema Corte, ADPF 54/DF, Pragmatismo

\section{Abstract}

Throughout its history, western thought and, especially, juridical thought have privileged reason over sentiments. This can be explained by the fact that reason has been based on invariability and eternity, whereas sentiments have been pictured as manifestations of inconstant and deceptive nature. Therefore, most contemporary views of approaching legal norms and the attitude of its users do not give sufficient attention to the influence of sentiments in the constitution of normative prescriptions, nor even take into consideration the influence of sensorial experiences in the process of making a juridical decision. However, the present article examined in detail the arguments used in the votes of the ten ministers of the Brazilian Supreme Federal Court (STF), during the judgement of the Claim of Non-compliance with the Fundamental Principle (ADPF) 54/DF, procedure which recognized the unconstitutionality of the interpretation whereby the interruption of pregnancy of an anencephalic fetus would be a motive for abortion, a behavior typified in articles 124, 126 and 128, paragraphs I and II of the Penal Code. The objective of this study was to analyze the decision of this emblematic case from a pragmatic and contextualist point of view, trying to identify the relevant role of sentiments as a basis used by the ministers of the STF when deciding hard cases. In what concerns the methodology used, the ADPF 54/DF was chosen because it gives three interesting characteristics: (1) touched on a polemical question, causing strong social and political controversy and having a decision which motivated a large literary production; (2) The STF, the highest court of appeal in Brazil and which is responsible for the interpretation of the Constitution, decided against the literal transcription of the Penal Code; (3) involved a non-unanimous decision, with significant divergences of argumentation, contrasting foundations, significant emotional burden, uncertainty and confusion 
when considering technical-scientific, ethical-moral, philosophical, religious and legal terms, all of which led the Court to consult specialists in diverse areas. In that way, it is seen how the Supreme Federal Court brought the sphere of sentiments into harmony with that of juridical dogmatics by applying a pragmatic method, using the experience of women carrying anencephalic fetuses as an argumentative basis, as well as the polemics coming from the Direct Action of Unconstitutionality (DAI) 3510/DF, interdisciplinarity with other areas of knowledge (medicine, psychology, religion), prudence and equity, while, on the other hand, freeing itself from the literal application of the law.

Keywords: Feeling , Law, Supreme Court, ADPF 54/DF , Pragmatism

\section{INTRODUÇÃO}

O pensamento ocidental e, particularmente, o pensamento jurídico, ao longo de sua história, privilegiou a razão em detrimento dos sentimentos. Isso se explica porque a razão sempre esteve calcada na invariabilidade, eternidade e origem divina, enquanto os sentimentos foram retratados como manifestações de caráter inconstante e enganoso.

Esse narcisismo da razão inerente ao mundo jurídico, excessivamente apegado à lógica formal e ao racionalismo, jamais permitiu a emergência de conteúdos que agregassem princípios, valores e conceitos oriundos de campos menos ortodoxos, como aquele no qual se situam os sentimentos humanos. Com efeito, a maioria das perspectivas contemporâneas de abordagem normativa do direito e da postura dos seus operadores não dá a devida atenção à influência dos sentimentos na constituição dos ordenamentos normativos, nem, tampouco, leva em conta a influência de experiências sensoriais nos processos de tomada de decisão jurídica.

Os operadores do direito e os jus-filósofos ao elaborarem seus conceitos de interpretação e aplicação das leis, de argumentação e racionalidade jurídica, acabam se afastando do mundo empírico e dos elementos que caracterizam a dimensão sensorial do humano.

No entanto, o presente artigo realizou um levantamento detalhado dos argumentos empregados nos votos dos dez ministros do Supremo Tribunal Federal brasileiro, apresentados durante o julgamento da Arguição de Descumprimento de PreceitoFundamental(ADPF)54/DF, processo quereconheceuainconstitucionalidade na interpretação segundo a qual a interrupção da gravidez de feto anencéfalo seria hipótese de aborto, conduta tipificada nos artigos 124, 126 e 128, incisos I e II, do Código Penal.

O objetivo do trabalho foi analisar, sob uma perspectiva pragmática e contextualista, o acórdão deste caso emblemático, na tentativa de identificar o relevante papel dos sentimentos como fundamento utilizado pelos ministros do STF 
ao decidir hard cases. Quanto à metodologia utilizada, a ADPF 54/DF foi escolhida porque apresenta três características interessantes: (1) abordou questão polêmica, havendo fortes controvérsias sociais e políticas sobre o aborto e tendo a decisão motivado uma grande produção literária; (2) o STF, máxima instância recursal no Brasil e a quem cabe a interpretação da Constituição, julgou de maneira contrária à transcrição literal do Código Penal, (3) tratou de decisão não-unânime, com significativas divergências na argumentação, fundamentos contrastantes, expressiva carga emocional, dubiedade e confusão ao considerar os termos técnico-científicos, ético-morais, filosóficos, religiosos e legais, o que levou a Corte a ouvir especialistas em diversas áreas.

Assim, constatou-se que o Supremo Tribunal Federal harmonizou a esfera dos sentimentos com àquela da dogmática jurídica, através da aplicação do método pragmático, utilizando como base argumentativa a experiência das gestantes de fetos anencéfalos, as polêmicas provenientes da Ação Direta de Inconstitucionalidade (ADI) 3510/DF, a interdisciplinaridade com outros saberes (a medicina, a psicologia, a religião), a prudência e a equidade, desvinculando-se, por outro lado, da aplicação literal da lei.

Desse modo, ao trazer a contribuição da filosofia pragmática para a esfera do direito, tem-se o entrelaçamento do ser e do o dever ser, do lógos e do pathos jurídicos, da norma e da vida. Embora na mitologia grega não haja referências ao relacionamento das divindades Thêmis (deusa da Justiça) e Eros (deus do Amor), no âmbito do Supremo Tribunal Federal brasileiro do século XXI, Thêmis, representando a dogmática jurídica, e Eros, símbolo da afetividade, encontram-se indissociavelmente unidos.

Nesse viés, o artigo procurou trilhar um caminho diverso ao considerar que uma abordagem do fenômeno jurídico não implica necessariamente o desprezo pelo humano, pois, apesar de se reconhecer a inescapável dogmaticidade do direito contemporâneo, é de fundamental importância trazer para o ambiente jurídico não só o texto, mas o contexto, o interlocutor, sua forma de vida e seus sentimentos, a partir de um horizonte pragmático.

Por último, como suporte teórico da pesquisa utilizou-se o pragmatismo jurídico de Benjamin Nathan Cardozo (1870-1938), juiz da Suprema Corte dos Estados Unidos, cuja obra, The Nature of the Judicial Process (1921), é o resultado das transcrições de quatro conferências proferidas na Universidade de Yale. Nesse livro, o filósofo liga a teoria à prática dos tribunais, deixando claro que o magistrado é um criador de direito, logo, capaz de dirigi-lo no sentido da maior utilidade social.

Ademais, ele não expõe o direito sob a ótica puramente positivista, mas como um fenômeno social, intimamente associado às demais dimensões da vida humana, não podendo o juiz, portanto, ficar apartado das contribuições das outras ciências sociais. Ao discorrer acerca do modo como o juiz decidia, Cardozo apresenta a figura do magistrado como um agente criativo, e considera o direito na 
sua pluralidade e como acontecimento coletivo, não como um saber isolado.

$\mathrm{O}$ direito, produto da práxis, tem todo o seu processo de produção informado por sentimentos, valores, crenças, preconceitos, ideias e interesses. Com isso, propõe-se que, não obstante o inquestionável, e sempre enaltecido, papel da razão nas questões jurídicas, não devemos dissociar essas duas instâncias, nem menosprezar o peso decisivo que nossa vida afetiva assume no lócus onde reina a justiça.

\section{O SENTIMENTO NO DIREITO: breve percurso histórico}

O direito, apesar de se apoiar em argumentos e métodos intelectualistas, é uma disciplina que apela essencialmente às emoções, às paixões e aos sentimentos. A preocupação pelos pilares e nuances emocionais relevantes é uma constante no pensamento jurídico ocidental, de suas origens até os dias atuais. A prova disso é que alguns filósofos, juristas, romancistas e sociólogos abordaram desde a antiguidade essa intrínseca afinidade entre o direito e a afetividade.

Nesse sentido, Aristóteles, filósofo grego do século IV a.C., expôs na "Política" (1985, I, 1253b), que é o sentimento de justiça o que serve para distinguir o homem do animal, uma vez que o senso do justo e do injusto, do bem e do mal, são específicos do ser humano:

a característica especifica do homem em comparação com os outros animais é que somente ele tem o sentimento do bem e do mal, do justo e do injusto e de outras qualidades morais, e é a comunidade de seres com tal sentimento que constitui a família e a cidade. [Grifou-se]

Cesare Beccaria, em “Dos Delitos e das Penas" (ed. digital, p. 25), sustentou que "toda lei que não for estabelecida sobre essa base [os sentimentos] encontrará sempre uma resistência à qual será constrangida a ceder. (...) Consultemos, pois, o coração humano; acharemos nele os princípios fundamentais do direito de punir". Barbey d'Aurevilly (2001), literata francês do século XIX, numa obra intitulada "Le bonheur dans le crime" (A felicidade no crime), apresentou uma íntima relação dos sentimentos com o direito penal.

Rudolf von Ihering (2009, p. 42-43) afirmou que a natureza e a importância do Direito se revelam quando o homem é atingido em seu direito, em sua personalidade, e aparece sob a forma de enfermidade moral: "Aqueles que não tiveram ocasião de medir pessoalmente esta dor não sabem o que é o direito, ainda que tenham em sua cabeça todo o Corpus júris; e isto por que não é a razão, mas o sentimento que pode resolver esta questão".

Émile Durkheim (2007, p. 68-69) dialogou com o direito e o sentimento, principalmente, com o denominado sentimento coletivo, na obra "As regras do 
método sociológico":

Com efeito, para que os sentimentos coletivos protegidos pelo direito penal de um povo, num momento determinado de sua história, consigam penetrar nas consciências que lhes eram então fechadas ou ter mais influência lá onde não tinham bastante, é preciso que eles adquiram uma intensidade superior à que possuíam até então. É preciso que a comunidade como um todo os sinta com mais ardor; pois eles não podem obter de outra fonte a força maior que lhes permite impor-se aos indivíduos que até então lhes eram mais refratários. [Grifou-se]

John Rawls, em "Uma teoria da justiça" (2003), explica que os sentimentos morais são os elementos motivadores dos comportamentos humanos e da coesão social. No entanto, a incursão na filosofia jurídica de algumas posições irracionalistas (PETRONE, 1928, p. 108 e ss. apud VERDÚ, 2004, p. 3), seguindo os caminhos de Nietzsche, Bergson e outros, foi praticamente ilustrativa, ainda que tenha servido para sublinhar as inconsequências da dogmática jurídica conceitualista.

\section{O DIREITO AO SENTIMENTO}

Ao refletir sobre o lugar dos sentimentos no âmbito jurídico, observase a importância da matéria, uma vez que é possível identificar elementos dessa intersecção em quase todas as suas subdivisões. No direito de família, por exemplo, os sentimentos estão presentes de forma abundante nos temas referentes ao casamento, processos de adoção, alienação parental, uniões estáveis, reconhecimento de famílias homoafetivas e monoparentais. Atualmente, é possível, inclusive, responsabilizar civilmente o genitor que abandona afetivamente sua prole, bem como o cônjuge infiel que provoca dano emocional no consorte.

Na seara constitucional, os sentimentos são tutelados quando o ordenamento jurídico rechaça o discurso do ódio, o bullying, o racismo, a homofobia e a xenofobia. A resolução dos hard cases em que há a colisão de direitos fundamentais também é uma questão em que geralmente se apela a argumentos que transcendem a razão, pois, no dizer de Ayres Britto, "os sentimentos estão na linha de partida do princípio da dignidade da pessoa humana" (Brasil, 2012, p. 264).

Ademais, no âmbito penal, a proteção da honra (arts. 138 a 145 do CP), do sentimento religioso (art. 208 do CP), do respeito aos mortos (art. 209 a 212 do $\mathrm{CP}$ ) são amostras que o direito reprime alguns comportamentos que vilipendiam os sentimentos. E quanto à sanção, não se pode olvidar que quando o réu é tomado por uma 'violenta emoção' sua pena será atenuada (art. 65, III, “c” do CP).

Além disso, os critérios de dosimetria e fixação da pena são subjetivos, não estando imunes aos sentimentos (art. 59 do CP) do juiz e da sociedade. No processo 
penal, também é possível reconhecer sentimentos bastante heterogêneos em seus atores (cf. SAUTEL, 2014, p. 2):

\begin{tabular}{l|l}
$\begin{array}{l}\text { Sentimentos do } \\
\text { acusado } \\
\begin{array}{l}\text { Sentimentos da } \\
\text { vítima }\end{array}\end{array}$ & $\begin{array}{l}\text { O ciúme, a ira, a ambição, a cobiça, a ganância } \\
\text { A vingança, o rancor, a injustiça, o ódio, o perdão }\end{array}$ \\
\hline $\begin{array}{l}\text { Sentimentos do juiz } \\
\begin{array}{l}\text { Sentimentos dos } \\
\text { jurados }\end{array}\end{array}$ & A justiça, a lealdade, a imparcialidade \\
\hline $\begin{array}{l}\text { Sentimentos do } \\
\text { público }\end{array}$ & $\begin{array}{l}\text { A consternação, o horror, a insegurança, o temor, a } \\
\text { perplexidade }\end{array}$
\end{tabular}

Percebe-se, assim, que o direito é mais uma questão de sentimento do que de racionalidade; entretanto, ele foi concebido para julgar esse fenômeno emocional de modo mais racional possível. O Direito Romano foi declarado como a "Ratio scripta". Com São Tomás de Aquino, as descrições da lei eterna e da lei positiva medievais ressaltavam a razão, distanciando-se das correntes voluntaristas (Duns Scoto, Guilherme de Ockham). O processo de racionalização e consequente formalização do direito, em todos os seus domínios, foi crescendo cada vez mais, conforme se avançava em direção ao Estado moderno e contemporâneo (VERDÚ, 2004, p. 1).

No entanto, se todo o direito está construído por causa do homem, há de se tomar este como razão e paixão, como ser que pensa e que sente, como racionalidade fundada sobre sentimento. Juízes são seres humanos que sentem emoções e expressam-nas continuamente. Ora os juízes expressam os sentimentos do autor ou do réu, ora os próprios sentimentos ou da sociedade. Todavia, a diferença entre os sentimentos que o juiz sente e aqueles que atribui à sociedade pode ser difícil estabelecer, pois o fato de exprimir o sentimento coletivo permite ao juiz garantir uma melhor aparência de imparcialidade.

Seguindo esta lógica, o foco deste artigo é analisar, sob uma perspectiva pragmática e contextualista, o acórdão do Supremo Tribunal Federal no célebre julgamento da ADPF 54/DF, para avaliar como esta corte expressou seus sentimentos. O Supremo Tribunal Federal foi escolhido como matéria de estudo porque, além de ser a máxima instância recursal no Brasil, é a quem cabe a interpretação da Constituição. Quanto ao tema, o aborto de fetos anencefálicos, objeto da ADPF 54/ $\mathrm{DF}$, foi eleito porque acarreta ainda forte carga emocional, dubiedade e confusão se se considerarem os termos técnico-científicos, ético-morais, filosóficos, religiosos e legais, o que levou o Supremo Tribunal a ouvir especialistas nas diversas áreas nas quais se estuda o tema. 


\section{OS SENTIMENTOS DO SUPREMO TRIBUNAL FEDERAL NA}

\section{ADPF 54/DF}

Segundo Magalhães (2013, p. 105), é difícil apontar o momento preciso em que a sociedade brasileira, como um todo, passou a acompanhar e compreender mais atentamente o significado e o impacto das decisões do Supremo Tribunal Federal em suas vidas. Não está claro se o marco inicial teria sido a criação da TV Justiça (2002), o caso Ellwanger (Brasil, 2003), os casos de infidelidade partidária (Brasil, 2007), de pesquisas em células-tronco embrionárias (Brasil, 2008) ou o Mensalão (Brasil, 2012). Mas, apesar da dificuldade em apontar apenas um, em meio a tantos episódios emblemáticos, é indiscutível que todos esses acontecimentos reforçaram o sentimento de participação da sociedade em julgados importantes e sensíveis para os direitos fundamentais do povo brasileiro.

Nesses julgamentos, a suprema corte brasileira pode exprimir seus sentimentos através de decisões polêmicas oriundas de questões controvertidas que dividiram a opinião pública. Para ilustrar esse fenômeno, analisou-se o acórdão do julgamento pelo Supremo Tribunal Federal da ADPF 54/DF (Brasil, 2012), com vistas a responder a seguinte questão: em que medida as decisões do STF apelam aos sentimentos para fundamentar seus acórdãos?

\subsection{UMA ANÁLISE DA ADPF 54/DF}

O caso a ser apresentado trata-se da Arguição de Descumprimento de Preceito Fundamental 54/DF (Brasil, 2012) em que a Confederação Nacional dos Trabalhadores na Saúde (CNTS) pleiteava a declaração de inconstitucionalidade na interpretação de interrupção de gravidez de feto anencéfalo como conduta tipificada nos artigos $124^{1}, 126^{2}$ e 128 , incisos I e $\mathrm{II}^{3}$, do Código Penal. Ou seja, o tribunal tinha de discutir, no mérito, um assunto delicado no que diz respeito ao direito constitucional à vida: a possibilidade, ou não, da antecipação terapêutica do parto de fetos diagnosticados com anencefalia (prática identificada por alguns juízes como o crime de aborto), bem como garantir tal direito sem a apresentação de requerimento judicial.

Antes do julgamento da ADPF 54/DF, foram realizadas audiências públicas com a presença de entidades representativas de diversos segmentos sociais,

1 Art. 124 - Provocar aborto em si mesma ou consentir que outrem lho provoque: Pena - detenção, de um a três anos.

2 Art. 126 - Provocar aborto com o consentimento da gestante: Pena - reclusão, de um a quatro anos.

3 Art. 128 - Não se pune o aborto praticado por médico: I - se não há outro meio de salvar a vida da gestante; II - se a gravidez resulta de estupro e o aborto é precedido de consentimento da gestante ou, quando incapaz, de seu representante legal. 
religiosos e científicos, entre os dias 26 e 28 de agosto de 2008, 4 e 16 de setembro de 2008. Inúmeros argumentos foram levantados acerca do significado do direito à vida perante o direito constitucional brasileiro e, consequentemente, apesar dos esforços dos ministros em evitar tal questão, vieram à tona dúvidas sobre a constitucionalidade da vedação legal do aborto fora das exceções legais previstas no Código Penal.

O Ministro Marco Aurélio (Brasil, 2012, p. 32-87), relator do processo, após sustentar a laicidade do Estado, discorrer sobre a condição médica do anencéfalo e o caráter não absoluto do direito à vida, ressaltou o aspecto psíquico que a gravidez de feto anencéfalo pode conduzir a mãe a um quadro emocional devastador:

a manutenção compulsória da gravidez de feto anencéfalo importa em graves danos à saúde psíquica da família toda e, sobretudo, da mulher. Enquanto, numa gestação normal, são nove meses de acompanhamento, minuto a minuto, de avanços, com a predominância do amor, em que a alteração estética é suplantada pela alegre expectativa do nascimento da criança; na gestação do feto anencéfalo, no mais das vezes, reinam sentimentos mórbidos, de dor, de angústia, de impotência, de tristeza, de luto, de desespero, dada a certeza do óbito. (...) Pesquisa realizada no hospital da Universidade de São Paulo, no período de janeiro de 2001 a dezembro de 2003, com pacientes grávidas de fetos portadores de anomalia incompatível com a vida extrauterina, dá conta de que $60 \%$ das entrevistadas não só experimentaram sentimento negativo - choque, angústia, tristeza, resignação, destruição de planos, revolta, medo, vergonha, inutilidade, incapacidade de ser mãe, indignação e insegurança - como também diriam a outra mulher, em idêntica situação, para interromper a gestação. [Grifou-se]

Além disso, em resposta àqueles que argumentaram que o sentimento de culpa pode advir da decisão de antecipar parto, Marco Aurélio replicou "caber à mulher, e não ao Estado, sopesar valores e sentimentos de ordem estritamente privada, para deliberar pela interrupção, ou não, da gravidez" [grifou-se]. Compete à mulher, no exercício do seu direito à privacidade, voltar-se para si mesma, refletir sobre as próprias concepções e tomar a decisão se deseja, ou não, prosseguir com a gestação. O direito nesse caso é o da autodeterminação. O Ministro finalizou seu voto salientando ser "inadmissível fechar os olhos e o coração ao que vivenciado diuturnamente por essas mulheres, seus companheiros e suas famílias" e julgou procedente o pedido com vistas a assegurar o exercício pleno da liberdade de escolha da mulher, em nome do direito à vida e à saúde da gestante, de modo a aliviá-la de sofrimento maior.

Em seguida, a Ministra Rosa Weber (Brasil, 2012, p. 88-144) mencionou que os paradigmas científicos da medicina não necessariamente devem ser utilizados 
pelo jurista, malgrado a estreita e mútua correlação entre tais ciências. Sustentou, ainda, que o conceito de vida no direito, próprio da dogmática, da legislação e da jurisprudência, não se confunde com aquele extraído da medicina, e que o direito positivo julga suficiente a declaração de morte encefálica para o indivíduo ser considerado morto, sendo desnecessário aguardar a falência cardiorrespiratória:

(...) ainda que o indivíduo possa ser mantido por algumas horas ou dias, ele jamais terá qualquer consciência, emoção, sentimento, capacidade de resposta ao (ou interação com) ambiente (mesmo que possa acontecer de, com morte cerebral declarada, apresentar determinados reflexos, como movimento de flexão dos dedos da mão, flexão do tronco, entre outros). [Grifou-se]

Em nome da autonomia da gestante, a Ministra defendeu que a saúde da mulher é um vetor importante na ponderação dos valores constitucionais e também votou pela procedência do pedido, considerando que a gestante tem o direito de escolher entre a manutenção ou interrupção da gravidez.

Em seu voto, o Ministro Joaquim Barbosa (Brasil, 2012, p. 145-153) também evocou a liberdade individual de cada mulher e ressaltou que "estudos multidisciplinares indicam que as reações emocionais dos pais após o diagnóstico de malformação fetal abrangem, os seguintes sentimentos: ambivalência, culpa, impotência, perda do objeto amado, choque, raiva, tristeza e frustraçãa" [grifouse]. Explicitou, ainda, que há diferentes graus de tutela do direito à vida (desde a fecundação à morte) e a partir do momento em que se demonstra a inviabilidade do anencéfalo, este deixa de ser amparado pelo ordenamento jurídico. Concluiu seu voto reconhecendo a atipicidade da conduta e a procedência do pedido com vistas a ser excluída do âmbito de incidência do art. 124 do Código Penal a antecipação terapêutica do parto de feto anencéfalo.

O Ministro Luiz Fux (Brasil, 2012, p. 154-171), por sua vez, empregando entusiasmo e sentimento, iniciou suas razões evidenciando a dor moral suportada pela gestante que carrega em seu ventre, durante nove meses, "um filho em relação ao qual ela assiste à missa de sétimo dia por uma imposição supostamente legal". Em seguida, disse:

Hoje de manhã, acordei e agradeci a Deus por poder contribuir com a humanidade por meio de uma decisão que pode conjurar tristezas, angústias, dores, aflições e, ao mesmo tempo, pedi a Deus que a razão e a paixão me acompanhassem no exercício desse mais alto apostolado que um ser humano pode se dedicar nesse mundo de Deus: a magistratura. [Grifou-se] 
O Ministro também fez referência a uma carta pungente na qual um jovem homem relata seu sofrimento e de sua esposa gestante quando assistiram durante noves meses ao funeral de seu filho. Ao término da carta, o homem suplica: "Ministro, compreenda essa dor!". Fux ponderou ainda que não é possível eleger a vida mais importante: a do feto ou a da mulher (dilema: pro-life versus pro-choice), mas que fosse garantido tanto o direito da gestante que escolhe manter a gestação e realizar o parto, como daquela que, com vistas a proteger a própria saúde física e psíquica, deseja interromper a gravidez. Por isso, votou pela procedência da ADPF 54/DF.

A Ministra Cármen Lúcia (Brasil, 2012, p. 172-236) citou a obra "Manuelzão e Miguilim" de Guimarães Rosa para dizer que a dignidade da mãe vai além dela mesma e do seu corpo:

quando se faz escolha pela interrupção do que poderia ser a vida de um momento ou a vida por mais um mês, não é escolha fácil, é escolha trágica sempre; é a escolha que se faz para continuar e para não parar; é a escolha do possível numa situação extremamente difícil. Por isso, acho que é preciso que se saiba que todas as opções como essa, mesmo essa interrupção, é de dor. A escolha é qual a menor dor; não é de não doer, porque a dor do viver já aconteceu, a dor do morrer também. Ela só faz a escolha possível nesse sentido. [Grifou-se]

Ademais, ressaltou os argumentos da autonomia da vontade da mulher, da inviabilidade do feto anencéfalo, da ausência de vida diante da inatividade cerebral e da angustia que acompanha a gestante e sua família nessa situação, uma vez que a questão não está no útero, mas na mente de cada pessoa. A Ministra concluiu afirmando que "o ser humano não é apenas corpo, menos ainda uma de suas partes. É um todo complexo". Ela acompanhou os demais Ministros e também julgou procedente a ADPF 54/DF.

O Ministro Ricardo Lewandowski (Brasil, 2012, p. 237-252) afirmou que o objeto de proteção do crime de aborto é a vida do nascituro. E tal proteção abrange, também, o portador de doenças congênitas ou com deformidades incuráveis, por isso, não legitima o aborto eugênico para antecipar a morte do feto com má formação, seja ela qual for. Complementou, ainda, que à época da promulgação do Código Penal, em 1940, a medicina já dispunha de métodos e técnicas para detectar eventual degeneração fetal. No entanto, o Congresso, representante da vontade do povo e dotado de legitimidade para alterar o Código Penal, manteve intacta a lei no tocante ao aborto. Diante disso, o Ministro votou em sentido contrário aos demais membro da corte, e julgou improcedente a ADPF 54/DF.

O Ministro Ayres Britto (Brasil, 2012, p. 254-266) destacou que a Constituição e o Código Penal padecem de ilogicidade, pois não há uma definição acerca do início da vida, o que inviabiliza a criminalização do aborto. Disse, ainda, 
que inexiste o crime de aborto se a interrupção da gravidez não é impeditiva da transformação do nascituro em pessoa humana em sentido biográfico: "o feto anencéfalo é uma crisálida que jamais, em tempo algum, chegará ao estágio de borboleta porque não alçará voo jamais". Considerou que os sentimentos estão na linha de partida do princípio da dignidade da pessoa humana e, ao impedir a gestante de optar pelo aborto, aqueles seriam ignorados. Os sentimentos, uma vez somatizados, teriam a força de arruinar qualquer estado de saúde física, psíquica e moral da mulher: "levar às últimas consequências esse martírio [a gestação] contra a vontade da mulher corresponde à tortura, a tratamento cruel". Arrematou seu voto julgando procedente o pedido para declarar a inconstitucionalidade da interpretação segundo a qual a interrupção da gravidez de feto anencéfalo é conduta tipificada no Código Penal brasileiro.

O Ministro Gilmar Mendes (Brasil, 2012, p. 267-309) iniciou seu julgamento afirmando tratar-se de "uma questão extremamente sensível que se submete à apreciação desta Corte", "um tema de múltiplas sensibilidades". Em seu voto, discorreu sobre o Estado laico e a sociedade aberta dos intérpretes da Constituição; pontuou o tratamento do aborto na jurisprudência de cortes estrangeiras, ressaltando que quase a metade dos países membros da Organização da Nações Unidas (ONU) reconhece a interrupção da gravidez na hipótese de anencefalia do feto; e, por último, teceu algumas considerações sobre a anencefalia e o aborto de fetos anencéfalos à luz do direito brasileiro. Quanto ao argumento de atipicidade da conduta do aborto, exposto na exordial, Gilmar Mendes rebateu que não seria uma hipótese de fato atípico, ante a evidente proteção jurídica que se confere ao nascituro (o feto anencéfalo pode nascer com vida, ainda que de curta duração), por isso, "tratar o aborto do feto anencéfalo como fato atípico afigurar-se-ia até mesmo ofensiva àquela parcela da sociedade que defende a vida e a dignidade desses fetos". Ademais, também não se poderia proteger o direito de praticar o aborto de anencéfalos com fulcro no princípio da dignidade, uma vez que o feto também é protegido por essa cláusula constitucional. No entanto, o Ministro manifestou-se pala procedência do pedido quando constatou que o parto antecipado de anencéfalos seria uma causa supralegal de exclusão de ilicitude e/ou culpabilidade, ao tutelar a saúde psíquica e emocional da gestante, tal qual na hipótese de gravidez resultante de estupro:

o aborto do feto anencéfalo tem por objetivo precípuo zelar pela saúde psíquica da gestante, uma vez que, desde o diagnóstico da anomalia (que pode ocorrer a partir do terceiro mês de gestação) até o parto, a mulher conviverá com o sofrimento de carregar consigo um feto que não conseguirá sobreviver, segundo a medicina afirma com elevadíssimo grau de certeza. [Grifou-se] 
O Ministro Celso de Mello (Brasil, 2012, p. 313-365) valeu-se de boa parte dos argumentos utilizados na Ação Direta de Inconstitucionalidade (ADI) 3510/ $\mathrm{DF}$, que versou sobre o tema da utilização de terapias celulares com células-tronco embrionárias, para reforçar que os direitos reprodutivos e da autonomia privada da mulher lhe permitem decidir sobre os momentos de interrupção da gestação. Ele expôs, ainda, que Poder Legislativo, influenciado por valores e sentimentos prevalecentes na sociedade brasileira, tem se mostrado contrário à necessidade de adequação do ordenamento nacional a essa realidade emergente das práticas e costumes sociais. Afirmou também que a interrupção da gravidez em caso de anencefalia fetal seria hipótese configuradora de causa supralegal de exclusão da culpabilidade apta a descaracterizar a delituosidade do fato. Nessa situação específica, a causa supralegal mencionada traduziria hipótese caracterizadora de inexigibilidade de conduta diversa, uma vez que inexistente motivo racional, justo e legítimo que possa obrigar a gestante a prolongar a gravidez e a expor-se a desnecessário sofrimento físico e/ ou psíquico, com grave dano à sua saúde e com possibilidade, até mesmo, de risco de morte. Ao final, julgou procedente a ADPF 54/DF para confirmar o pleno direito da mulher gestante de interromper a gravidez de feto comprovadamente portador de anencefalia.

O último Ministro a se pronunciar foi Cezar Peluso (Brasil, 2012, p. 375415) que iniciou suas considerações distinguindo a ADI 3510/DF da ADPF 54/DF. Naquele julgamento, tinha-se a figura do embrião excedente, isto é, que não fora introduzido no útero e jamais viria a sê-lo. Assim sendo, a ideia de vida humana estaria afastada, uma vez ausente o fenômeno do processo vital que a caracteriza. No entanto, para o Ministro, os fetos anencéfalos, a menos que já estejam mortos, são inequivocamente dotados do processo contínuo de vida e regidos pela lei natural que lhe é imanente: "o simples e decisivo fato de o anencéfalo ter vida e pertencer à imprevisível espécie humana (...) não rouba a inata dignidade humana, nem o transforma em coisa ou objeto material desvalioso ao juízo do Direito e da Constituição da República". O Ministro disse, ainda, que não haveria nenhum critério capaz de justificar o sacrifício da vida do feto em nome da tutela do sentimento materno cujo objeto seria apenas livrar-se de uma dor sem culpa:

a interpretação há de ser, antes, ampla e generosa na proteção ao valor supremo do ordenamento jurídico, sobretudo quando, como no caso, eventual mutilação hermenêutica do espectro dessa tutela seria sustentada e imposta para favorecer mero sentimento doloroso doutros seres humanos, como se tal estado psíquico, a que estão sujeitas todas as pessoas, constituísse título jurídico hábil para, sob fundamento de excessiva insuportabilidade, justificar o extermínio da vida de inocentes indefesos. [Grifou-se] 
Cezar Peluso também foi de encontro ao argumento segundo o qual a gravidez de feto anencéfalo produz tamanho sofrimento à mãe, que obrigá-la a manter a gestação até o fim seria comparável à tortura, pois faltaria ao caso a circunstância elementar de inflicção 'proposital' de sofrimento. Segundo o Ministro, não haveria um responsável por aplicar a tortura a mãe: seria o feto anencéfalo, o Poder Legislativo ou o Poder Judiciário? Além disso, para o Ministro:

O sofrimento em si não é alguma coisa que degrade a dignidade humana; é elemento inerente à vida humana. $O$ remorso também é forma de sofrimento. E o que o sistema jurídico não tolera não é o sofrimento em si, porque seria despropósito que o sistema jurídico tivesse a absurda pretensão de erradicar da experiência humana as fontes de sofrimento. Nem quero discorrer sobre o aspecto moral e ético - não me interessa - de como o sofrimento pode, em certas circunstâncias, até engrandecer pessoas, pois isso não releva à discussão do caso. Só quero relembrar que o sistema jurídico repudia, em relação ao sofrimento, apenas os atos injustos que o causem. O sofrimento provindo da prática de um ato antijurídico, esse não pode ser admitido pela ordem normativa. Mas não é esse o caso de eventual sofrimento materno, ou pelo menos não o é de regra. [Grifou-se]

Ato contínuo, discordando da maioria dos Ministros, Cezar Peluso reconheceu que a ação de eliminação intencional da vida intrauterina de anencéfalos corresponderia ao tipo penal do aborto e julgou improcedente a ADPF 54/DF. Ao término do julgamento, o Supremo Tribunal Federal decidiu pela interpretação de que não se configura crime de aborto a antecipação de parto de fetos anencéfalos. A votação obteve, portanto, o seguinte placar:

\begin{tabular}{c|c} 
AFAVOR DO ABORTO & CONTRA OABORTO \\
\hline Ayres Britto, Cármen Lúcia, Celso de Mello, & Cezar Peluso e Ricardo \\
Gilmar Mendes, Joaquim Barbosa, Luiz Fux, Marco & Lewandowski \\
Aurélio e Rosa Weber &
\end{tabular}

Como se observou em diversas passagens, a questão dos sentimentos foi amplamente abordada, ora os dos próprios Ministros e da sociedade, ora os da gestante e do feto. A Corte reconheceu, mesmo em votos divergentes, a situação difícil em que se encontravam e foi possível constatar que o Supremo Tribunal Federal não se mantém apático e exprime certos sentimentos nos julgamentos de hard cases, apesar de nem sempre tutelá-los, como restou evidente nos votos divergentes dos Ministros Ricardo Lewandowski e Cezar Peluso.

Verificou-se ainda que, na maioria das vezes, os Ministros apegaram-se sobretudo à sensibilidade, sem abandonar a razão, para decidir o caso concreto, 
adotando uma postura pragmática, isto é, demonstrando que o discurso jurídico não é, e não pode ser, construído como mera subsunção, com base apenas na ideia de incidência automática e infalível da norma jurídica, corroborando a ideia de Clóvis Falcão (2014, p. 162) que "a natureza dos problemas éticos requer uma abordagem sensivelmente distinta da que propõe o ideal analítico / quantitativo / geometrizante / cartesiano".

\section{PRAGMATISMO JURÍDICO: UM DIÁLOGO ENTRE THÊMIS E EROS}

- $\quad$ Ler artigo de G. Browne - O Pragmatismo de Charles S. Pierce: conceitos e distinções.

- $\quad$ Ler antigo de L. Freitas - Um diálogo entre Pragmatismo e Direito

A filosofia dualista de Immanuel Kant, calcada na teoria dos dois mundos, que isola natureza e espírito, ser e consciência, real e ideal, objeto e sujeito, ser e dever-ser, ocupou lugar de destaque no pensamento ocidental, especialmente em Hans Kelsen (Adeodato, 1996, p. 32). Como neokantista, Kelsen desenvolveu a Teoria Pura do Direito, tomando o pressuposto da intransponibilidade absoluta entre as esferas do ser e do deve-ser, e separou uma perspectiva descritiva de uma prescritiva (Kelsen, 1999, p. 54).

Para Kelsen, o juízo do ser e o juízo do dever-ser seriam totalmente independentes e cada um seguiria seu método específico. Entretanto, o alto grau de teorização e o apego excessivo às formas e às categorias a priori desenvolvido por esse filósofo não foram suficientes para solucionar os problemas do ponto de vista da prática, considerando que o positivismo lógico-normativo, do qual o autor foi figura de destaque, apartou-se por completo da vida real (Kaufmann, 2002, p. 182).

Em oposição a esse dogmatismo tradicional, o pragmatismo surgiu, a partir dos encontros do Clube Metafísico de Boston ${ }^{4}$, para suplantar o dualismo e unir o mundo dos fatos e o mundo dos direitos em um único plano. O pragmatismo constituiu-se numa ameaça a toda cultura ocidental e, em particular, à cultura francesa (cartesianismo) e sua preocupação recaiu, principalmente, contra o racionalismo e às posturas intelectualistas, uma vez que estes estabelecem que a verdade é objetiva, transcendente, impessoal e universal. "Ligar pensamento à existência, ligar o

4 Dá-se o nome de pragmatismo a um movimento filosófico, ou grupo de correntes filosóficas, que teve origem nos Estados Unidos, no seio do "Metaphysical Club" de Boston, nas últimas décadas do século $X X$, e sua força de expressão, tanto na América quanto na Europa, atingiu o auge nos primeiros quinze anos do presente século. Criado em 1870, o Clube Metafísico ganhou esse nome por ironia de seus membros, uma vez que a metafísica era considerada fora de moda. O principal objetivo do pragmatismo era erradicar a verborragia filosófica sem sentido, substituindo, em seu caso, especulações metafísicas pelo que consideravam uma ciência empírica sólida. (WAAL, 2007, p. 22-23.) 
pensamento à vida, eis a ideia fundamental do Pragmatismo" (Durkheim, s/d, p. 31) .

Com o nascimento do pensamento pragmatista deixou-se, portanto, de existir o abismo epistemológico entre verdade e realidade, existência e pensamento, essência e aparência. Para os pragmatistas, não há dualismos, mas um único mundo que se manifesta da maneira que o vemos.

Ademais, a verdade não é uma transcrição fidedigna da realidade, não é abstrata, nem requer um intelecto puro para apreendê-la, mas é fruto da criatividade humana e possui diferentes atributos: é aberta, dinâmica, viva, maleável, mutável e provisória. Com efeito, os pragmatistas rejeitam a crença dogmática de que a verdade seja imutável, una, ideal e invariável, o que lhes possibilita buscar sempre um aperfeiçoamento e refinamento do significado (Stroh, 1972, p. 115).

$\mathrm{O}$ método pragmático revela a impossibilidade de se pensar através dos dualismos recorrentes que atormentam a filosofia: analítico x sintético, dedução $\mathrm{x}$ indução, subjetivo x objetivo, razão x sentimento. Todos esses termos entraram em voga nas últimas décadas, por serem amparados pela neurociência: os hemisférios esquerdo e direito do cérebro, um dedicado aos cálculos, o outro à intuição; um realista, o outro criativo; um para a ciência, o outro para a arte. Inclusive, o próprio Ministro Ayres Britto (Brasil, 2012, p. 261) faz referência a tais dicotomias em seu voto, no julgamento da ADPF 54/DF:

A mente é um dos hemisférios do cérebro; o feto anencéfalo não tem mente e não tem cérebro. $\mathbf{O}$ cérebro, segundo a neurociência e a física quântica, é binário, como tudo o mais na vida; tudo é dual, tudo se nos dá em dicotomias, em dualismos: o perto e o longe, o claro e o escuro, o largo e o estreito, a alegria e a tristeza, o amor e o ódio, o pensamento e o sentimento, o concreto e o abstrato; tudo. Por isso que o cérebro também tem dois hemisférios, basicamente: o hemisfério esquerdo é chamado de mente. [Grifou-se]

Contrário a qualquer metafísica e à veneração da verdade, o método pragmático procura acabar com tais disputas que, de outro modo, seriam intermináveis (James,1979, p. 17-18). Essas múltiplas antíteses, tomadas em conjunto, foram institucionalizadas em um dualismo cultural que é a preocupação central do pensamento pragmático como um todo.

Afora os perigos já indicados pelo pragmatismo, sobre o conceito dogmático de verdade una, impessoal e exterior à vida, as ameaças de intolerância

5 Durkheim, apesar de seu posicionamento em oposição à filosofia pragmática, sustenta que o pragmatismo recusa a ideia segundo a qual o homem apenas seja o descobridor da verdade. Ao contrário, a capacidade criadora humana permite que o homem nomeie, classifique, reoriente, inovando a realidade a partir de sua consciência criadora. Desse modo, ao passo que o homem se vê desafiado pela realidade, torna-a cada vez mais desenvolvida com suas experiências. (HENNING, 2006, p. 41). 
diante da pluralidade, um ceticismo paralisador diante da vida, um conhecimento impiedoso por desprezar as nuances da realidade, agrega-se mais outro: o risco do conformismo, pela crença de que a verdade seja igual para todos. Na realidade, os pragmáticos negam qualquer metafísica e sustentam uma única verdade possível: só é possível considerar a esfera do humano.

A imposição de verdades pré-estabelecidas, a necessidade de certezas, de segurança intelectual, de códigos e leis rigorosas, foram infundidas nos homens pelos dogmáticos racionalistas. Tais ficções enfraquecem o que é próprio da vida como a mutabilidade, a inconstância e a plasticidade que fazem do universo uma realidade inacabada em elaboração constante (HENNING, 2006, p. 43).

Desse modo, trazendo a contribuição do pragmatismo para o Direito, temse a unificação entre o ser e o dever ser, do lógos e do pathos jurídicos, da norma e da vida. Embora na mitologia grega não haja referências ao relacionamento das divindades Thêmis ${ }^{6}$ e Eros ${ }^{7}$, no âmbito do Supremo Tribunal Federal do século XXI, Thêmis, representante da dogmática jurídica, e Eros, símbolo da afetividade, estão indissociavelmente unidos. O sentimento, está ganhando, pouco a pouco, foros de juridicidade, passível da relevância, quantificação e, dados os efeitos do capitalismo, de monetarização.

Ademais, muitas vezes, representa-se a deusa da Justiça, Thêmis, sob a forma de uma mulher, com os olhos vendados, segurando uma balança de dois pratos. Enquanto a venda representa imparcialidade, os dois pratos representam os argumentos das partes. Thêmis é, portanto, representada como objetiva e cega, sem preconceitos e sentimentos. O pragmatismo jurídico, no entanto, reconhece que os juízes são seres humanos que não podem realizar uma justiça cega como poderia, talvez, os deuses. Mas, na medida em que o juiz é um ser humano livre e aberto a se deixar guiar por sentimentos, evidências e argumentos, Eros não é mais obstáculo para a imparcialidade de Thêmis e a decisão judicial transcende o racional.

\section{CONCLUSÃO}

Apontada como questão nuclear da dogmática jurídica a resolução dos conflitos, consolidada pelo princípio moderno da proibição do "non liquet", parece legítimo sustentar que o juiz moderno, atrelado ao decidir, encarnou a ideia cartesiana de método, levando à construção de uma enrijecida dogmática jurídica, apartada da

6 Deusa das leis eternas, da justiça emanada dos deuses, representando, sobretudo, o caráter sagrado das leis e, consequentemente, a necessidade de cumpri-las a qualquer custo para evitar o castigo divino. (Donizetti, 2014)

7 Deus grego do amor, sempre à espreita dos belos de corpo e de alma, com sagazes ardis. Eros representa a paixão, o arrebatamento violento, a interferência no ponto mais íntimo das relações humanas, na relação com o outro, no compartilhamento do afeto, no cuidado entre os amantes, na vida conduzida a dois. Demanda escolha, compromisso, renúncia. (Donizetti, 2014) 
práxis e distante da complexidade das sociedades contemporâneas. Nesse contexto, afirma o Prof. George Browne Rêgo (2009, p. 25-56) que:

Um olhar retrospectivo sobre as nossas práticas judiciais deixa entrever que, a metodologia aplicada ao direito ainda se assenta no modelo subsuntivo que remonta ao século XIX. Esse modelo, no qual a decisão jurídica resulta dogmaticamente do texto legal ou de uma estrita submissão dos fatos à lógica, opõe-se ao método pragmático. Ele parece não resistir a uma análise mais profunda dos seus postulados. Na maioria das vezes, os casos em que as normas jurídicas não se conformam aos fatos por mera subsunção, dado a singularidade de cada evento e a impossibilidade do legislador de prever a infinidade de ocorrências fáticas que a realidade venha a provocar, resultam no aparecimento de situações consideradas aporéticas. [Grifou-se]

Nessa via, este artigo trilha um caminho diverso ao considerar que uma abordagem do fenômeno jurídico não implica necessariamente o desprezo pelo humano ${ }^{8}$, pois, apesar de se reconhecer a inescapável dogmaticidade do direito contemporâneo, é de fundamental importância trazer para o ambiente jurídico não só o texto, mas o contexto, o interlocutor e sua forma de vida, dentro de uma perspectiva pragmática.

Tal concepção pode ser sintetizada, conforme a Profa. Luciana Browne (2014, p. 479), como uma metodologia que "privilegia a experiência, a equidade e o bom senso, através da análise de cada caso concreto, o que só poderia ocorrer por meio da alforria do sistema puramente formal e legalista atualmente utilizado por grande parte dos juízes e Tribunais".

Assim, a transformação da dogmática jurídica levou atualmente à inadmissibilidade da abordagem do processo de decisão judicial como mero instrumento de subsunção das normas vigentes no ordenamento jurídico. A norma passou a ter um caráter construído de sentido, não sendo mais possível tratar o processo decisório-interpretativo como simples descoberta ou revelação de algo intrínseco. Com efeito, a fim de estabelecer um elo entre o pragmatismo e os casos

8 A modernidade deixou como legado a concepção de que um pensamento dogmático rejeita elementos zetéticos e vice-versa, levando o processo de decidir a um rompimento entre teoria e prática, frente às necessidades de estabilidade e segurança jurídica tão cobiçadas no mundo ocidental (Lins, 2014, p. 101-102). Nesse sentido, Ferraz Jr. adverte para a necessidade do pensamento dogmático não deixar de enfrentar o problema do comportamento humano em suas implicações na elaboração e na aplicação do direito. Desse modo, a dificuldade de se pensar uma aproximação construtiva entre teoria e prática não se consegue a partir da exclusão radical das questões zetéticas do discurso dogmático, como querem os normativistas da escola kelseniana (Kelsen, 1998, p. 1), nem pela redução das questões dogmáticas às questões zetéticas, como pretendem os adeptos de sociologismos e psicologismos jurídicos (Ferraz Jr., 1980, p. 83). 
concretos, impende transcrever as palavras do Prof. George Browne Rêgo (2009, p. 45-46):

Redirecionando o problema para o campo do direito, observa-se que cada caso insere-se num conjunto de circunstâncias específicas e, assim, tem a sua própria história. Sua solução rejeita portanto modelos ortodoxos e sua análise varia em função de um maior domínio possível dos elementos que comparecem à situação conjuntural, associado ao esforço imaginativo no sentido de encontrar soluções mais apropriadas e convenientes para cada caso. Os antecedentes são também muito importantes. O somatório de todas essas condições possibilita que se chegue a decisões mais realistas e razoáveis em boa parte dos casos, apesar de existirem os chamados "hard cases" no dizer de Dworkin. Entretanto, esses, não correspondem à maioria, e mesmo assim, devem ser enfrentados, a partir de algum nível de remodelamento teórico, o que supõe, maior criatividade e inovação. [Grifou-se]

A conceitualização, racionalização, formalização e sistematização do direito são indispensáveis e supõem um indubitável progresso jurídico. Sem dogmática jurídica, sem conceitos, categorias, figuras e postulados jurídicos, a ciência do direito não existiria. No entanto, a conceitualização do direito não suprime a necessidade e do sentimento jurídico, pois sabe-se que o sentimento do justo e do injusto nem sempre se satisfaz com a formalização do direito (VERDÚ, 2004, p. 5).

Do mesmo modo que a normatividade jurídica puramente lógica não gera efetividade, um sentimento jurídico intensamente passional ou patético pode dissolver a normatividade. Deve-se aceitar o pluralismo das visões do mundo e propor uma plausível perspectiva de mediação entre os extremos que estão sendo colocados.

É preciso, portanto, realizar uma adequada ponderação da normatividade e do sentimento jurídicos, equidistantes do racionalismo e do romantismo em todas as suas exteriorizações. A efetividade de um ordenamento jurídico vigente depende, portanto, da consonância aristotélica entre as dimensões do saber e da prudência humanos, como pontuou o Prof. George Browne Rêgo (2009, p. 46):

Acerca do inovar, caberia aqui, retomar o velho paradigma aristotélico segundo o qual, os ingredientes que compõem o ato de julgar e de procurar fazê-lo com justiça consistem em integrar e harmonizar essas duas dimensões extremamente nobres do ser humano essas virtudes superiores que são a Sophia e a Phronesis, ou seja, a sabedoria e a prudência.

Para concluir, é possível constatar que o Supremo Tribunal Federal 
vem harmonizando a esfera dos sentimentos com a dogmática jurídica, através da aplicação do método pragmático em julgamento de hard cases, a exemplo do paradigmático caso da ADPF 54/DF.

Esse desiderato constitucional só se tornou possível porque a suprema corte brasileira julgou o caso utilizando como base argumentativa a experiência das gestantes de fetos anencéfalos e de seus familiares, as polêmicas provenientes da ADI 3510/DF, a interdisciplinaridade com outros saberes (a medicina, a psicologia, a religião), a prudência, a equidade, os princípios fundamentais do estado democrático de direito, desvinculando-se, por outro lado, da aplicação literal da lei.

Nesse sentido, o próprio Ministro Cezar Peluso (2012, p. 375), apesar do voto divergente, utilizou-se de um argumento pragmático para enfatizar que a decisão de cada magistrado ultrapassa a frieza da norma e "envolve a formação, a cultura, o modo de ver, o modo de ser de cada magistrado, de cada homem e de cada mulher, que está atrás de cada toga".

Para a análise do problema, a junção do conceitual com o histórico frente à experiência em estudos de casos, longe de ser conflitante, tornou-se harmonioso do ponto de vista hermenêutico, contribuindo, assim, para uma decisão justa frente às circunstâncias do caso concreto.

Pelo exposto, traz-se à colação as reflexões do Juiz da Suprema Corte Americana, Benjamin Nathan Cardozo (2002, p. 540), em que pretende definir o papel e função de um julgador, a saber:

É uma questão de grau se a lei que toma minha propriedade e limita minha a conduta, prejudica minha liberdade de maneira indevida. Assim, dever de um juiz se torna também uma questão de grau, e ele é um juiz útil ou um juiz medíocre quando calcula a medida de forma exata ou imprecisa. Ele deve equilibrar todos os seus ingredientes, sua filosofia, sua lógica, suas analogias, sua história, seus costumes, seu senso do direito e todo o resto, e acrescentando um pouco aqui e retirando um pouco ali, deve determinar do modo mais sábio que puder qual peso fará pender a balança. (...) Após ter terminado o cansativo processo de análise, deve haver para todo juiz uma nova síntese que ele terá de fazer por si mesmo. O máximo que ele pode esperar é que, com muito pensamento e estudo, com anos de prática como advogado ou juiz e com a ajuda daquela graça interior que chega de vez em quando ao eleito de qualquer vocação, a análise possa ajudar um pouco a tornar a síntese verdadeira. [Grifou-se] 


\section{REFERÊNCIAS}

ADEODATO, João Maurício. Filosofia do direito: uma crítica à verdade na ética e na ciência. São Paulo: Saraiva, 1996.

ARISTÓTELES. Política. Trad. Mário da Gama Kury. Brasília: Editora Universidade de Brasília, 1985.

BARBEY D'AUREVILLY, Jules. Le bonheur dans le crime. Paris: Maxi Livre, 2001.

BECCARIA, Cesare. Dos delitos e das penas. Ed. eletrônica Ridendo Castigat Mores. Disponível em http://www.ebooksbrasil.org/ . Acesso em 10 set. 2014.

BRASIL. Decreto-lei n 2.848, de 7 de dezembro de 1940. Código Penal. Disponível em http://www.planalto.gov.br/ . Acesso em 10 set. 2014.

BRASIL. Supremo Tribunal Federal. Ação direta de inconstitucionalidade 3510/DF. Requerente: Procurador-Geral da República. Requerido: Presidente da República. Relator: Min. Ayres Britto. Brasília, 2008.

BRASIL. Supremo Tribunal Federal. Ação penal 470/MG. Autor: Ministério Público Federal. Réu: José Dirceu de Oliveira e Silva e outros. Relator: Min. Joaquim Barbosa. Brasília, 2012 (a).

BRASIL. Supremo Tribunal Federal. Arguição de descumprimento de preceito fundamental 54 / DF. Requerente: Confederação Nacional dos Trabalhadores na Saúde - CNTS. Intimado: Presidente da República. Relator: Min. Marco Aurélio. Brasília, 2012 (b).

BRASIL. Supremo Tribunal Federal. Habeas corpus 82.424-2/RS. Paciente: Siegfried Ellwanger. Impetrante: Werner Cantalício João Becker. Coator: Superior Tribunal de Justiça. Relator: Min. Moreira Alves. Brasília, 2003.

BRASIL. Supremo Tribunal Federal. Mandado de segurança 26602/DF. Impetrante: Partido Popular Socialista - PPS. Impetrado: Presidente da Câmara dos Deputados. Relator: Min. Eros Grau. Brasília, 2007.

BRITTO, Carlos Ayres. Discurso de posse à presidência do STF. - Brasília, 2012. Disponível em www.stf.jus.br/arquivo/cms/noticiaNoticiaStf/anexo/ DiscursoAyresBritto.pdf . Último acesso em 15 set. 2014.

BROWNE, Luciana Pereira Gomes. Ensaio sobre pragmatismo jurídico à luz do direito civil-constitucional: a importância do método pragmático para o sistema judicial brasileiro. In: FALCÃO, Clóvis; NÓBREGA, Flavianne; BASTOS, Ronaldo (Org.). Pragmatismo jurídico: fundamentos e métodos de uma doutrina interdisciplinar. Recife: Editora UFPE, 2014, p. 479-496. 
CARDOSO, Benjamin Nathan. The Nature Of The Judicial Process (With Notes). Wildside Press LLC, 2010.

DONIZETTI, Elpidio. Entre Thêmis e Eros: a judicialização do afeto e o direito. Disponível em: http://elpidiodonizetti.jusbrasil.com.br/artigos/121940202/entrethemis-e-eros-a-judicializacao-do-afeto-e-o-direito . Ultimo acesso em 22.set.2014

DURKHEIM, Émile. As regras do método sociológico. Trad. Paulo Neves. 3. ed. São Paulo: Martins Fontes, 2007.

DURKHEIM, Émile. Sociologia, pragmatismo e filosofia. Trad. Evaristo Santos. Porto: Rés, s/d.

FALCÃO, Clóvis. Bergson, Dewey, James e a ousadia pragmatista. In: FALCÃO, Clóvis; NÓBREGA, Flavianne; BASTOS, Ronaldo (Org.). Pragmatismo jurídico: fundamentos e métodos de uma doutrina interdisciplinar. Recife: Editora UFPE, 2014, p. 161-177.

FERRAZ JR., Tercio Sampaio. Função social da dogmática jurídica. São Paulo: Ed. Revista dos Tribunais, 1980.

HENNING, Leoni Maria Padilha. O pragmatismo na obra de Émile Durkheim "Sociologia, pragmatismo e filosofia": perspectiva de análise, críticas e contribuições do autor. In: Cognitio-Estudos: Revista Eletrônica de Filosofia - Pontifícia Universidade Católica de São Paulo. São Paulo, Volume 3, Número 1, janeiro/junho, 2006, p. 39 - 53.

IHERING, Rudolf von. A luta pelo direito. Trad. Ivo de Paula. São Paulo: Pillares, 2009.

JAMES, William. Pragmatismo e outros textos. Trad. Jorge Caetano da Silva, Pablo Rubén Mariconda. São Paulo: Abril Cultural, 1979.

KAUFMANN, Arthur. A problemática da filosofia do direito ao longo da história. In: KAUFMANN, A; HASSEMER, W. (Orgs.). Introdução à filosofia do direito e à teoria do direito contemporâneas. Trad. Marcos Keel. Fundação Calouste Gulbenkian: Lisboa, 2002, p. 57-208.

KELSEN, Hans. Teoria pura do direito. Trad. João Baptista Machado. 6 ed. São Paulo: Martins Fontes, 1998.

LINS, Alessandra Macedo. Considerações sobre a possibilidade de um diálogo construtivo entre dogmática jurídica e experiência hermenêutica. In: FALCÃO, Clóvis; NÓBREGA, Flavianne; BASTOS, Ronaldo (Org.). Pragmatismo jurídico: fundamentos e métodos de uma doutrina interdisciplinar. Recife: Editora UFPE, 2014, p.101-114.

MAGALHÃES, Breno Baía. O próximo degrau: o direito à vida na jurisprudência 
do STF e a criminalização do aborto. In: ANJOS FILHO, Robério Nunes dos (Org). STF e direitos fundamentais: Diálogos contemporâneos. Salvador: Juspodivm, 2013, p. 105-138.

PETRONE, Igino. La última fase de la filosofia del derecho en Alemania. Trad. Cristóbal de Reyna. Madrid: Saturnino Calleja Fernández, 1928.

RAWLS, John. A theory of justice. Cambridge: Harvard University Press, 2003.

REGO, George Browne. O pragmatismo como alternativa à legalidade positivista: o método jurídico-pragmático de Benjamin Nathan Cardozo. In: Revista Duc In Altum - Caderno de Direito, vol. 1, no 1, jul-dez. 2009, p. 21-57.

ROBERT, Marie-Pierre. Les sentiments de la Cour suprême du Canada révélés dans ses jugements en matière criminelle. In: FORTIER, Vincent; LEBEL-GRENIER, Sébastien (Dir.). Les sentiments et le droit: rencontres juridiques montpelliersherbrooke. Sherbrooke: Éditions Revue de droit de l'Université de Sherbrooke, 2012, p. 167-177.

SAUTEL, Oliver. Le droit répressif, un droit sans sentiments? Disponível em http://halshs.archives-ouvertes.fr/halshs-00755911 . Último acesso em 11 set. 2014.

STROH, Guy W. A Filosofia Americana: Uma Introdução de Edwards a Dewey. São Paulo: Cultrix. 1972.

VERDÚ, Pablo Lucas. O sentimento constitucional: aproximação ao estudo do sentir constitucional como modo de integração política. Trad. Agassiz Almeida Filho. Rio de Janeiro: Forense, 2004.

WAAL, Cornelis de. Sobre pragmatismo. Trad. Cassiano Terra Rodrigues. São Paulo: Edições Loyola, 2007. 